OPEN ACCESS

Edited by:

Timothy E. Albertson, UC Davis Medical Center,

United States

Reviewed by:

Athanasia Papazafiropoulou,

Tzaneio Hospital, Greece

Leah Reznikov,

University of Florida, United States

Timotius Ivan Hariyanto,

University of Pelita Harapan, Indonesia

Andree Kurniawan,

University of Pelita Harapan, Indonesia

*Correspondence:

Hong Fan

fanhongfan@qq.com

${ }^{\dagger}$ These authors have contributed equally to this work

Specialty section:

This article was submitted to Respiratory Pharmacology,

a section of the journal

Frontiers in Pharmacology

Received: 27 June 2021 Accepted: 25 November 2021 Published: 09 December 2021

Citation:

Zhang T, Tong $X$, Zhang S, Wang $D$, Wang L, Wang Q and Fan H (2021) The Roles of Dipeptidyl Peptidase 4 (DPP4) and DPP4 Inhibitors in Different Lung

Diseases: New Evidence.

Front. Pharmacol. 12:731453.

doi: 10.3389/fphar.2021.731453

\section{The Roles of Dipeptidyl Peptidase 4 (DPP4) and DPP4 Inhibitors in Different Lung Diseases: New Evidence}

\author{
Tianli Zhang ${ }^{\dagger}$, Xiang Tong ${ }^{\dagger}$, Shijie Zhang, Dongguang Wang, Lian Wang, Qian Wang and \\ Hong Fan *
}

Department of Respiratory and Critical Care Medicine, West China Hospital/West China School of Medicine, Sichuan University, Chengdu, China

CD26/Dipeptidyl peptidase 4 (DPP4) is a type II transmembrane glycoprotein that is widely expressed in various organs and cells. It can also exist in body fluids in a soluble form. DPP4 participates in various physiological and pathological processes by regulating energy metabolism, inflammation, and immune function. DPP4 inhibitors have been approved by the Food and Drug Administration (FDA) for the treatment of type 2 diabetes mellitus. More evidence has shown the role of DPP4 in the pathogenesis of lung diseases, since it is highly expressed in the lung parenchyma and the surface of the epithelium, vascular endothelium, and fibroblasts of human bronchi. It is a potential biomarker and therapeutic target for various lung diseases. During the coronavirus disease-19 (COVID-19) global pandemic, DPP4 was found to be an important marker that may play a significant role in disease progression. Some clinical trials on DPP4 inhibitors in COVID-19 are ongoing. DPP4 also affects other infectious respiratory diseases such as Middle East respiratory syndrome and non-infectious lung diseases such as pulmonary fibrosis, lung cancer, chronic obstructive pulmonary disease (COPD), and asthma. This review aims to summarize the roles of DPP4 and its inhibitors in infectious lung diseases and non-infectious diseases to provide new insights for clinical physicians.

Keywords: dipeptidyl peptidase 4 (DPP4), DPP4 inhibitors, infectious lung disease, non-infectious disease, COVID-19, pulmonary fibrosis

\section{INTRODUCTION}

Dipeptidyl peptidase 4 (DPP4), also called CD26, is a serine protease that is widely distributed in various organs and cells. DPP4 can also be found in the plasma and body fluids in a soluble form (Shao et al., 2020). It participates in various physiological and pathological processes of the body, such as inflammation, energy metabolism, immune regulation, cell adhesion, and apoptosis (Klemann et al., 2016). DPP4 inhibitor, as a hypoglycemic agent, was approved by the Food and Drug Administration (FDA) for the treatment of type 2 diabetes mellitus (T2DM). Recent studies have found more biological functions of DPP4 beyond glucose control (Hildebrandt et al., 2001; Jae-Hwi; Ohnuma et al., 2011; Schuetz et al., 2015; Jang et al., 2017). DPP4 is frequently expressed on the surface of the epithelium, vascular endothelial cells, and alveolar macrophages in the lung (Meyerholz et al., 2016). In addition, more evidence has shown the underlying functions of DPP4 and its inhibitors in infectious lung diseases and non-infectious lung diseases (Meyerholz et al., 2016; Shiobara et al., 2016; Suzuki et al., 2017; Bishnoi et al., 2019). Here, we summarized the emerging roles of DPP4 and DPP4 inhibitors in lung diseases to provide new insights into clinical work. 


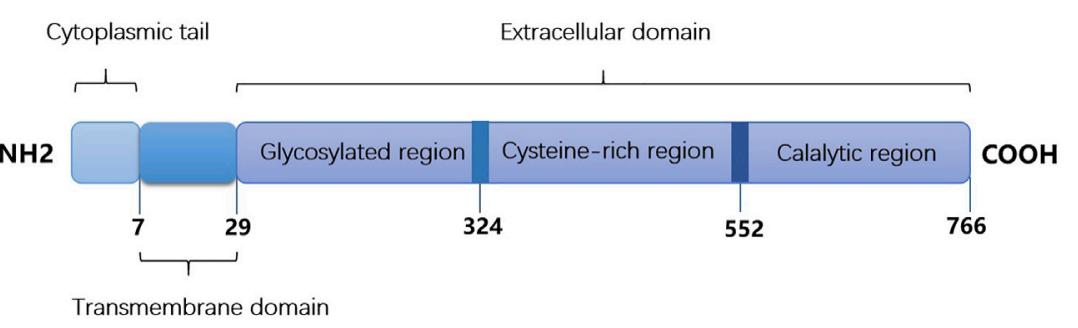

FIGURE 1 | The main structure of DPP4/CD26. It consists of cytoplasmic tail (1-6 amino acids), transmembrane domain (7-29 amino acids) and extracellular domain (30-766 amino acids).

\section{LITERATURE SEARCH}

We performed a literature search in PubMed database up to October 23, 2021. The key search terms were as follows: "DPP4 or DPPIV or CD26", "DPP4 inhibitor or Vildagliptin or Saxagliptin or Sitagliptin or Alogliptin," "respiratory disease or lung disease," "lung cancer," "pulmonary fibrosis," "pulmonary hypertension," "asthma," "chronic obstructive pulmonary disease or COPD," "SARS-CoV2 or COVID-19," "Middle East Respiratory Syndrome or MERS". After an initial screening of the title and abstract, the full text of all the relevant articles in English language about the roles of DPP4 and DPP4 inhibitors in lung diseases were included. Additionally, we also included some relevant articles from references to ensure a comprehensive search. Finally we reviewed the available literature and presented it.

\section{DPP4 MOLECULE AND EXPRESSION}

As a member of the subfamily S9B of serine peptidases, DPP4/ CD26 is a highly conserved type II transmembrane glycoprotein, which consists of a 6-residue N-terminal cytoplasmic tail, a 22 amino acid transmembrane, and extracellular domain (Matteucci and Giampietro, 2009). Figure 1 shows the main structure of DPP4/CD26. As a hydrophobic domain and a part of the putative signal peptide, the transmembrane domain is not cleaved during synthesis. The extracellular domain cleaves dipeptide after the second position from the N-terminus of peptides with proline or alanine, which indicates dipeptidyl peptidase activity (Fleischer, 1994). Soluble DPP4 can also be found in body fluids due to the removal of intracellular and transmembrane regions, and it still has enzymatic activity (Klemann et al., 2016). Many peptides, such as cytokines, chemokines, and neuropeptides, can be cut by membrane or soluble DPP4, which further regulates their biological functions (Anderluh et al., 2016; Beckers et al., 2017).

DPP4 is extensively expressed in many tissues, such as the lung, intestine, kidney, liver, brain, thymus, bladder, pancreas, spleen, uterus, lymph node, epithelium, endothelium, and immune cells (Gorrell, 2005). DPP4 was demonstrated to be broadly distributed in the lung parenchyma and the surface of the epithelium, vascular endothelium, and fibroblasts of human bronchi, indicating that DPP4 may play a significant role in regulating physiological and pathological functions in the lung (Van Der Velden and Hulsmann, 1999). DPP4 has been reported to be expressed in immune cells such as T cells, B cells, natural killer (NK) cells, and macrophages (Nieto-Fontarigo et al., 2019). $\mathrm{CD}^{+} \mathrm{T}$ cells express DPP4 more frequently than $\mathrm{CD}^{+} \mathrm{T}$ cells, which might be related to the $\mathrm{T}$ helper type 1 (Th1)-like phenotype (Willheim et al., 1997). DPP4 was detected to be low in NK cells, while it increased after cytokine stimulation (Yamabe et al., 1997). Likewise, DPP4 can be detected in approximately $50 \%$ of B cells after activation (Bühling et al., 1995). Therefore, more effects of DPP4 in the immune system have been observed.

\section{DPP4 FUNCTIONS}

DPP4 plays an important role in regulating body metabolism since it cleaves and inactivates peptides, such as glucagon-like peptide-1 (GLP-1), incretin hormones, and glucose-dependent insulinotropic polypeptide (GIP). And DPP4 inhibitors have been widely used to treat T2DM. In addition, circulating DPP4 concentration was demonstrated to be higher in individuals with obesity than in those with normal body weight (Rohmann et al., 2021). Barchetta et al. found higher circulating DPP4 activity in non-alcoholic fatty liver disease (NAFLD) patients than in non-NAFLD patients (Barchetta et al., 2021). Sitagliptin, a DPP4 inhibitor, was reported to decrease plasma apolipoprotein $\mathrm{B}$ and triglyceride levels in patients with T2DM, indicating the function of DPP4 in regulating lipid metabolism (Tremblay et al., 2011).

DPP4 also participates in inflammation, as it can cleave chemokines and cytokines (Klemann et al., 2016). Wronkowitz et al. observed that sDPP4 could increase the secretion of proinflammatory cytokines, such as interleukin (IL)-6, IL-8, and MCP-1, and that inflammation could be prevented by inhibiting DPP4 in vitro (Wronkowitz et al., 2014). sDPP4 might stimulate inflammation through the upregulation of toll-like receptors (D. S. Lee et al., 2016). Sitagliptin has been demonstrated to decrease serum DPP4 activity and reduce the production of proinflammatory cytokines in LPS-induced lung injury in mice (Kawasaki et al., 2018).

DPP4 is a surface marker expressed in senescent cells (Kim et al., 2017). Chen et al. reported increased DPP4 levels in senescent endothelial cells and aging arteries, and DPP4 inhibition could decrease the production of senescent markers such as p21 and p53 (Z. Chen et al., 2020b). In addition, the 
binding of DPP4 and adenosine deaminase (ADA) can activate the DPP4/ADA pathway to modulate $\mathrm{T}$ cell functions (Hatano et al., 2013). DPP4 has also been demonstrated to be related to $\mathrm{CD}^{+} \mathrm{T}$ cell co-stimulation, $\mathrm{B}$ cell activation, macrophage polarization, and $\mathrm{NK}$ cell proliferation, playing an emerging role in modulating immune functions (Shingu et al., 2003; Yan et al., 2003; Hatano et al., 2013; Zhuge et al., 2016). Regarding its role in the immune system, DPP4 was shown to participate in the pathogenesis of autoimmune diseases (rheumatoid arthritis, inflammatory bowel disease) and graft-versus-host disease (GVHD) (Pan et al., 2021).

\section{DPP4 IN INFECTIOUS LUNG DISEASES}

\section{SARS-Cov-2 Infection}

COVID-19 is caused by SARS-Cov-2 and has been a pandemic disease threatening the public health of the global population since December 2019. Naveen et al. predicted the molecular model of SARS-Cov-2 and found that the S1 domain of SARS-Cov-2 spike glycoprotein might interact with DPP4 of host cells directly, which implies the effects of DPP4 in COVID-19 (Vankadari and Wilce, 2020). Tai et al. identified the receptor-binding domain (RBD) in the S1 region of SARSCov-2, which can bind to angiotensin-converting enzyme 2 (ACE2) in humans or bats. However, the RBD of the S1 domain did not exhibit binding activity to DPP4 in human cells (Tai et al., 2020). Although there is a lack of evidence for the combination of the S1 protein with DPP4, the roles of DPP4 and DPP4 inhibitors in COVID-19 have been increasingly realized. Diabetes is a common comorbidity of COVID-19 and is a risk factor for poor prognosis (F. Zhou et al., 2020a). Higher levels of DPP4 might be correlated with the occurrence and severity of COVID-19 (Radzikowska et al., 2020). DPP4 inhibition may decrease lung damage by reducing the production of cytokines, exhibiting anti-inflammatory effects and regulating glucose metabolism (Solerte et al., 2020a). Acute respiratory distress syndrome (ARDS) is the leading cause of death in COVID-19 patients, and DPP4 inhibitors may be a new treatment approach because they can decrease the production of inflammatory factors such as IL- $1 \beta$, TNF- $\alpha$, and IL-6 (Kawasaki et al., 2018). A retrospective study including 338 patients showed that sitagliptin, a DPP4 inhibitor, can reduce mortality and improve clinical outcomes in COVID-19 patients with T2DM. In addition, plasma C-reactive protein (CRP) and procalcitonin levels were also reduced in sitagliptin-treated patients compared to those in the control group, which indicated its anti-inflammatory and immunomodulatory effects (Solerte et al., 2020b). However, a multicenter retrospective analysis in China reported that there was no significant decrease in the occurrence of poor outcomes when using DPP4 inhibitors in COVID-19 patients with T2DM compared to non-users. Moreover, they did not observe significant differences in cytokine concentrations like TNF- $\alpha$ and IL-6 between the two groups (J. H. Zhou JH. et al., 2020). Strollo drew a similar conclusion after analyzing data from the Italian National Institute of Health (Strollo et al., 2021). The difference in the occurrence of mechanical ventilation or death was found to be insignificant between the DPP4 inhibitor and non-DPP4 inhibitor treatment groups (27.7\% versus $28.6 \%$, respectively) (Roussel et al., 2021). Hariyanto performed a meta-analysis on the application of DPP4 inhibitors in COVID-19 patients with T2DM, and the results showed that there was no beneficial outcome compared to patients without DPP4 inhibitor treatment (Hariyanto and Kurniawan, 2021). The results of a meta-analysis conducted by Pal and Rakhmat both demonstrated that DPP4 inhibitors could reduce mortality and improve the outcome of these patients (Pal et al., 2021; Rakhmat et al., 2021). However, the majority were retrospective, observational studies, and the confounding factors were not well balanced, including inclusion criteria and baseline characteristics such as comorbidity and inflammation levels. However, these results are controversial. Thus, large-scale, randomized controlled clinical trials are needed, and some clinical trials are ongoing or recruiting. Table 1 summarized the results of the clinical effects of DPP4 inhibitors in COVID-19 patients with T2DM in recent studies.

\section{MERS}

Middle East respiratory syndrome (MERS) was first reported in Saudi Arabia in 2012 (Zaki et al., 2012). As a receptor, membrane DPP4 can bind to the S1 domain in MERS-CoV and mediate virus entry into host cells (N. Wang et al., 2013). As the DPP4 enzymatic position is different from the binding site (blades 4 and 5), DPP4 inhibitors such as vildagliptin and sitagliptin were ineffective in preventing MERS-CoV infection (Raj et al., 2013). Anti-DPP4 antibodies targeting the binding site of DPP4, such as YS110, blocked the entry of MERS-CoV (Ohnuma et al., 2013). Adenosine deaminase (ADA) can competitively bind to DPP4 to prevent the combination of DPP4 with the S1 domain of MERS-CoV (Raj et al., 2014). Therefore, ADA has become a potential agent to block viral infection. In addition, the role of soluble DPP4 (sDPP4) was demonstrated. Contrary to the primary expectation, sDPP4 levels were found to be lower in MERS patients than in healthy individuals, which indicates that exogenous sDPP4 may be a new approach to treat MERS (Inn et al., 2018). Abdullah confirmed that increased levels of sDPP4 in serum indicated higher resistance to MERS-CoV infection in vitro, and recombinant soluble human DPP4 (shDPP4) proteins can reduce the infection in mice (Algaissi et al., 2019). Recombinant shDPP4 might be a promising agent for MERS therapy, and more evidence is needed.

\section{DPP4 IN NON-INFECTIOUS LUNG DISEASES}

\section{Pulmonary Fibrosis}

Idiopathic pulmonary fibrosis (IPF) is a chronic progressive respiratory disease characterized by respiratory failure at the final stage. Irreversible lung injury and limited treatment options have caused high mortality, with a survival rate of only $20 \%$ over 5 years (Richeldi et al., 2017). DPP4 was found to be a marker of activated fibroblasts, and DPP4 inhibition 
TABLE 1 | Clinical outcomes of DPP4 inhibitors in COVID-19 patients with T2DM.

\begin{tabular}{|c|c|c|c|c|}
\hline Reference & Research type & Country & Sample size (users/non-users) & $\begin{array}{c}\text { Intensive care or } \\
\text { mortality (users/non-users) }\end{array}$ \\
\hline Solerte et al. (2020a) & Retrospective & Italy & $338(169 / 169)$ & $18 \% / 37 \%$ \\
\hline J. H. Zhou et al., 2020b & Retrospective & China & $444(111 / 333)$ & $1.8 \% / 3.3 \%$ \\
\hline \multirow[t]{2}{*}{ Rhee et al. (2021) } & HIRA database & Korea & $832(263 / 569)$ & $3.4 \% / 4.4 \%$ \\
\hline & NHIS database & Korea & $704(175 / 529)$ & $8 \% / 11.5 \%$ \\
\hline Y. Chen et al., 2020a & Retrospective & China & $120(20 / 100)$ & $25 \% / 14 \%$ \\
\hline Mirani et al. (2020) & Retrospective & Italy & $90(11 / 79)$ & $9.1 \% / 46.8 \%$ \\
\hline Wargny et al. (2021) & Retrospective & France & $2794(615 / 2179)$ & $18.3 \% / 21.3 \%$ \\
\hline Fadini et al. (2020) & Retrospective & Italy & $85(9 / 76)$ & $11.1 \% / 13.9 \%$ \\
\hline Noh et al. (2021) & Cohort & - & $586(453 / 133)$ & $10.4 \% / 16.5 \%$ \\
\hline Pérez-Belmonte et al. (2020) & Retrospective & Spain & $1589(180 / 1409)$ & $41.7 \% / 31.2 \%$ \\
\hline Roussel et al. (2021) & Cohort & France & $2449(596 / 1853)$ & $9.7 \% / 11.7 \%$ \\
\hline Silverii et al. (2021) & Retrospective & Italy & $159(13 / 146)$ & $38.5 \% / 37.0 \%$ \\
\hline Israelsen et al. (2021) & Retrospective & Denmark & $928(284 / 644)$ & $10.6 \% / 3.3 \%$ \\
\hline Cariou et al. (2020) & Retrospective & France & 1317 (285/1032) & $9.5 \% / 10.9 \%$ \\
\hline
\end{tabular}

HIRA, health insurance review and assessment service; NHIS: national health insurance service.

attenuated kidney fibrosis, dermal fibrosis, and liver fibrosis (Gangadharan Komala et al., 2016; Lay et al., 2019; S. Y.; Lee et al., 2020; Soare et al., 2020). Yang found that the DPP4 inhibitor vildagliptin can ameliorate pulmonary fibrosis by inhibiting the production of extracellular matrix (ECM) and inflammatory cells in mice (Liu and Qi, 2020). Another experiment performed by Suzuki et al. showed that DPP4 was increased in pulmonary vascular endothelial cells (PVECs) in pulmonary fibrosis models. Vildagliptin exhibited anti-fibrotic effects by inhibiting endothelial-to-mesenchymal transition (EndMT) in vivo and in vitro (Suzuki et al., 2017). In addition, epithelial and endothelial senescence has been reported to participate in pulmonary fibrosis, suggesting that anti-aging drugs may be effective (Schafer et al., 2017; Yao et al., 2021). DPP4 inhibition can also alleviate cellular senescence because it is a marker of senescent cells ( $Z$. Chen et al., 2020b). However, whether DPP4 inhibition can ameliorate pulmonary fibrosis via an anti-senescence mechanism is unknown. And it is still unclear about the effects of DPP4 inhibition in patients with pulmonary fibrosis.

\section{Pulmonary Hypertension}

Pulmonary hypertension is defined as elevated pulmonary arterial pressure $>25 \mathrm{mmHg}$, which affects approximately $1 \%$ of people worldwide, especially the elderly (Hoeper et al., 2016). Pulmonary hypertension is characterized by abnormal proliferation of endothelial cells and smooth muscle cells (SMCs), which eventually develops into right ventricular failure (Anderluh et al., 2019). DPP4 was found to be highly expressed in pulmonary arterial SMCs, and the Akt/mTORC1 and NF- $\kappa$ B pathways were demonstrated to mediate the development of pulmonary arterial SMC and hypoxia-induced pulmonary hypertension (Li et al., 2019). Xu et al. found that the DPP4 inhibitor sitagliptin decreased the infiltration of inflammatory cells and EndMT and ameliorated pulmonary arterial remodeling in rats, in which the PTEN-Akt-MAPK signaling pathway may play a role in progression ( $\mathrm{Xu}$ et al., 2018). In addition, a GLP-1 receptor antagonist was reported to neutralize the effects of DPP4 inhibition in pulmonary hypertension, which indicated that GLP-1 participated in the protective effects of DPP4 inhibitors to improve pulmonary arterial remodeling (J. Wang et al., 2019). Pirozzi et al. reported the effects of the DPP4 inhibitor vildagliptin in treating a 74-year-old female patient with T2DM and pulmonary hypertension. They observed an improvement in pulmonary symptoms and a reduction in systolic pressure of the right ventricle (SPRV) after 6 months (Fontes Pirozzi et al., 2017). DPP4 inhibitor probably exerted its role in pulmonary hypertension by promoting vasodilatation of the pulmonary artery and producing anti-inflammatory effects. Thus, DPP4 inhibition might be a potential therapeutic target for pulmonary hypertension, and clinical trials are needed.

\section{Asthma}

Bronchial asthma is characterized by chronic airway inflammation, with eosinophils, mast cells, neutrophils, and $\mathrm{T}$ lymphocyte infiltration. DPP4 levels are elevated in airway epithelial cells in asthma patients, and DPP4 can stimulate the proliferation of lung fibroblasts and bronchial SMCs in vitro (Shiobara et al., 2016). Kruschinski found that DPP4-dependent $\mathrm{T}$ cells were recruited to the lung in a rat asthma model, while in DPP4-deficient rats $\mathrm{T}$ cells obviously decreased (Kruschinski et al., 2005). This indicates that DPP4 may participate in the occurrence of asthma by regulating $\mathrm{T}$ cells. Interleukin-13 (IL13), secreted by Th2 cells, has been shown to be related to airway inflammation and allergy in asthma (Mitchell et al., 2010). A whole-transcriptome RNA sequencing study of nasal epithelial cells in children with asthma indicated that the DPP4 gene had a positive relationship with IL-13 mRNA level (Poole et al., 2014). In addition, DPP4 mRNA was shown to be induced by IL-13, indicating the potential role of DPP4 in asthma (Ranade et al., 2016). The DPP4 inhibitor sitagliptin can ameliorate airway remodeling by decreasing the production of IL-13 and the number of inflammatory cells and fibrotic-related factors such as TGF- $\beta$ and NF- $\kappa B$ in mice with chronic asthma (Nader, 2015). Another DPP4 inhibitor, saxagliptin, was reported to alleviate 
TABLE 2 | DPP4 expressions in lung cancer tissue or cells.

\begin{tabular}{|c|c|c|c|}
\hline References & Location & $\begin{array}{c}\text { SDPP4 } \\
\text { level or activity }\end{array}$ & $\begin{array}{c}\text { mDPP4 } \\
\text { level or activity }\end{array}$ \\
\hline Sedo et al. (1991) & Human lung cancer tissue & Low & - \\
\hline Wesley et al. (2004) & Human NSCLC cell lines (H28, H226, H441) & - & Low \\
\hline \multirow[t]{2}{*}{ Dimitrova et al. (2012) } & Human lung adenocarcinoma cell (A549) & - & Low \\
\hline & Human lung squamous cell carcinoma cell (SK-MES-1) & - & Low \\
\hline \multirow[t]{3}{*}{ Jang et al. (2019) } & Human lung cancer tissue & - & High \\
\hline & Human lung adenocarcinoma cell (H460) & - & High \\
\hline & Mouse lung adenocarcinoma cell (LLC) & - & High \\
\hline
\end{tabular}

airway inflammation in ovalbumin (OVA)-induced asthma in mice via the NF-kB and TLR4 pathways (Helal et al., 2019). However, a retrospective study conducted by Colice showed that there was no significant difference in the asthma control rate between DPP4 inhibitor users and non-users in asthma patients with T2DM. This might be related to the non-specific distribution of oral DPP4 inhibitor (Colice et al., 2017).

\section{COPD}

Chronic obstructive pulmonary disease (COPD) is a common respiratory disease that usually occurs in the elderly and in smokers. Inflammation of the airway and disordered immune functions facilitate the pathogenesis of COPD (Barnes et al., 2003). sDPP4 levels were demonstrated to be lower in COPD patients than in non-COPD patients, and it was expected to be a biomarker for the diagnosis of COPD (Somborac-Bačura et al., 2012; Chang et al., 2016). In contrast, Seys and others found DPP4 mRNA and protein levels were higher in smokers and COPD patients, and DPP4 increase was mainly located in alveolar epithelial cells rather than bronchial and bronchiolar epithelium. In addition, DPP4 level was also related to the stage of COPD and smoking status (Seys et al., 2018). The differences in DPP4 expression in the serum and lungs were unclear. The GLP-1 receptor agonist was found to be effective in decreasing the mortality of COPD female mice, suggesting that the GLP-1 receptor agonist is a promising agent for COPD therapy (Viby et al., 2013). Therefore, DPP4 inhibition may prevent the degradation of GLP-1 by DPP4 and play a role in COPD. However, further experiments and clinical trials should be performed.

\section{Lung Cancer}

Several studies have examined DPP4 expression in various malignancies to determine the role of DPP4 in tumor progression. However, the expression of DPP4 and its functions in tumors differ according to tumor type (Havre et al., 2008). The expression of DPP4 in colorectal cancer, malignant mesothelioma, and hematological malignancies is high and is related to tumor progression (Sato et al., 2005; Pang et al., 2010; Okamoto et al., 2014). DPP4 has been shown to be a tumor suppressor in other cancers, such as melanoma and ovarian cancer (Wesley et al., 1999; Kajiyama et al., 2002). The differences in DPP4 effects might be attributed to the tumor microenvironment and the complex functions of the molecule (Pro and Dang, 2004). Accordingly, as a malignant tumor with high morbidity and mortality, lung cancer is classified into small cell lung cancer (SCLC) and non-small cell lung cancer (NSCLC). DPP4 expression and its role in lung cancer remains controversial. sDPP4 levels are lower in lung cancer tissues than in normal tissues (Sedo et al., 1991). The mRNA and protein expression levels of DPP4 were both decreased in human NSCLC cells compared to normal lung epithelial cells (Wesley et al., 2004). Dimitrova also found that DPP4 activity was lower in human adenocarcinoma cell and squamous cell carcinoma cells than in normal fetal lung-derived P cells (Dimitrova et al., 2012). However, DPP4 expression varies according to the different histologic subtypes of lung cancer. Another study reported that DPP4 activity was high in human lung cancer tissue as well as in human and mouse lung adenocarcinoma cell lines. In addition, vildagliptin can exhibit anti-tumor effects, possibly via regulating macrophage and NK cell activity (J. H. Jang et al., 2019). DPP4 inhibition has been reported to improve progression-free survival (PFS) in advanced airway and colorectal cancer patients with T2DM (Ali et al., 2019). A national database study performed by Bishnoi et al. found that the combined use of DPP4 inhibitors and metformin can significantly increase the survival of lung cancer patients (Bishnoi et al., 2019). The DPP4 inhibitor vildagliptin was also shown to suppress the pulmonary metastasis of colorectal cancer in mice (J. H. Jang et al., 2015). Table 2 listed DPP4 expressions in different lung cancer tissues or cells.

The association between DPP4 and malignancy is still debated, and the underlying mechanisms are complex. On the one hand, DPP4 may act as a tumor suppressor in malignant diseases. A study showed that decreased expression of DPP4 in NSCLC cells indicated its tumor suppressor effect, which might be independent of its enzymatic activity (Wesley et al., 2004). Increased DPP4 expression mediates high CD44 and FAP- $\alpha$ expression (Wesley et al., 2004), which could exert suppressive effects on tumor growth and metastasis (Gao et al., 1997; Herrlich et al., 2000). Beckenkamp considered that DPP4 can inhibit tumor metastasis through its enzymatic activity via cleaving and inactivating stromal cell derived factor-1 (SDF-1) (Beckenkamp et al., 2016). In contrast, DPP4 may participate in the carcinogenesis of malignancy. It has been shown that DPP4 participates in tumor growth and invasion and is dependent on its interactive functions with other key molecules and its enzymatic effects. The combination of DPP4 with plasminogen 2-epsilon could promote the secretion of matrix metalloproteinases (MMPs), which are involved in tumor invasion (Gonzalez- 
Gronow et al., 2001). DPP4 can also exert its tumor progressive effect through induction of epithelial-mesenchymal transition (EMT) and upregulation of EMT markers such as N-cadherin, Slug, Twist, and vimentin (Beckenkamp et al., 2016). Thus, DPP4 function is altered according to specific location, histologic type of tumor, tumor microenvironment, and cofactors. Because of their controversial effects, further studies are needed to clarify the possible roles of DPP4 and DPP4 inhibitors in lung cancer.

\section{CONCLUSION AND PROSPECTIVES}

DPP4 is widely expressed in the membranes of the epithelium, endothelium, and fibroblasts of human bronchi. DPP4 and its inhibitors have been shown to play pivotal roles in lung diseases, such as COVID-19 and pulmonary fibrosis. Therefore, targeting DPP4 may provide a novel approach for treating lung diseases in the future.

However, localizing and targeting DPP4 remains a challenge because of its wide distribution, pleiotropic effects, and interaction with other molecules. DPP4 inhibitors can exert systemic effects in the body, and adverse effects are unavoidable. In addition, targeting the enzymatic activity using DPP4 inhibitors or targeting DPP4 protein using anti-DPP4 antibody still requires further study. For instance, DPP4 plays a complicated role in lung cancer of different histologic types via interplay with other key molecules and immune regulation. Thus, it is essential to explore the interaction of

\section{REFERENCES}

Algaissi, A., Agrawal, A. S., Han, S., Peng, B. H., Luo, C., Li, F., et al. (2019). Elevated Human Dipeptidyl Peptidase 4 Expression Reduces the Susceptibility of hDPP4 Transgenic Mice to Middle East Respiratory Syndrome Coronavirus Infection and Disease. J. Infect. Dis. 219 (5), 829-835. doi:10.1093/infdis/jiy574

Ali, A., Fuentes, A., Skelton, W. P., Wang, Y., Mcgorray, S., Shah, C., et al. (2019). A Multi-center Retrospective Analysis of the Effect of DPP4 Inhibitors on Progression-free Survival in Advanced Airway and Colorectal Cancers. Mol. Clin. Oncol. 10 (1), 118-124. doi:10.3892/ mco.2018.1766

Anderluh, M., Kocic, G., Tomovic, K., Kocic, H., and Smelcerovic, A. (2019). DPP-4 Inhibition: A Novel Therapeutic Approach to the Treatment of Pulmonary Hypertension? Pharmacol. Ther. 201, 1-7. doi:10.1016/j.pharmthera.2019.05.007

Anderluh, M., Kocic, G., Tomovic, K., Kocic, R., Deljanin-Ilic, M., and Smelcerovic, A. (2016). Cross-talk between the Dipeptidyl Peptidase-4 and Stromal CellDerived Factor-1 in Stem Cell Homing and Myocardial Repair: Potential Impact of Dipeptidyl Peptidase-4 Inhibitors. Pharmacol. Ther. 167, 100-107. doi:10.1016/j.pharmthera.2016.07.009

Barchetta, I., Ceccarelli, V., Cimini, F. A., Barone, E., Sentinelli, F., Coluzzi, M., et al. (2021). Circulating Dipeptidyl Peptidase-4 Is Independently Associated with the Presence and Severity of NAFLD/NASH in Individuals with and without Obesity and Metabolic Disease. J. Endocrinol. Invest. 44 (5), 979-988. doi:10.1007/s40618-020-01392-5

Barnes, P. J., Shapiro, S. D., and Pauwels, R. A. (2003). Chronic Obstructive Pulmonary Disease: Molecular and Cellular Mechanisms. Eur. Respir. J. 22 (4), 672-688. doi:10.1183/09031936.03.00040703

Beckenkamp, A., Davies, S., Willig, J. B., and Buffon, A. (2016). DPPIV/CD26: a Tumor Suppressor or a Marker of Malignancy? Tumour Biol. 37 (6), 7059-7073. doi:10.1007/s13277-016-5005-2
DPP4 with the tumor microenvironment, which may provide a new DPP4-targeted therapy strategy for lung cancer patients. Anti-DPP4 antibodies are a new future research topic. As previously mentioned, anti-DPP4 antibodies targeting the binding site of DPP4, such as YS110, blocked the entry of MERS-CoV (Ohnuma et al., 2013). The targeting of the DPP4 protein itself may be valuable for the development of vaccines for MERS and other viral infections. Therefore, further experimental and clinical studies are needed to explore the role of DPP4 in lung diseases to identify novel treatment approaches.

\section{AUTHOR CONTRIBUTIONS}

TZ, XT, SZ, DW, LW, QW and HF collaboratively conceptualized this manuscript. TZ wrote the first draft of this manuscript. All authors contributed to the review and approved the submitted version.

\section{FUNDING}

This study was supported by 1.3 .5 project for disciplines of excellence-Clinical Research Incubation Project, West China Hospital, Sichuan University (2019HXFH008), China Postdoctoral Science Foundation (2020M673259), and PostDoctor Research Project, West China Hospital, Sichuan University (2020HXBH013).

Beckers, P. A. J., Gielis, J. F., Van Schil, P. E., and Adriaensen, D. (2017). Lung Ischemia Reperfusion Injury: the Therapeutic Role of Dipeptidyl Peptidase 4 Inhibition. Ann. Transl Med. 5 (6), 129. doi:10.21037/atm.2017.01.41

Bishnoi, R., Hong, Y. R., Shah, C., Ali, A., Skelton, W. P., Huo, J., et al. (2019). Dipeptidyl Peptidase 4 Inhibitors as Novel Agents in Improving Survival in Diabetic Patients with Colorectal Cancer and Lung Cancer: A Surveillance Epidemiology and Endpoint Research Medicare Study. Cancer Med. 8 (8), 3918-3927. doi:10.1002/cam4.2278

Bühling, F., Junker, U., Reinhold, D., Neubert, K., Jäger, L., and Ansorge, S. (1995). Functional Role of CD26 on Human B Lymphocytes. Immunol. Lett. 45 (1-2), 47-51. doi:10.1016/0165-2478(94)00230-o

Cariou, B., Hadjadj, S., Wargny, M., Pichelin, M., Al-Salameh, A., Allix, I., et al. (2020). Phenotypic Characteristics and Prognosis of Inpatients With COVID19 and Diabetes: The CORONADO Study. Diabetologia 63 (8), 1500-1515. doi:10.1007/s00125-020-05180-X

Chang, X. Y., Yang, Y., Jia, X. Q., Wang, Y., Peng, L. N., Ai, X. H., et al. (2016). Expression and Clinical Significance of Serum Dipeptidyl Peptidase IV Chronic Obstructive Pulmonary Disease. Am. J. Med. Sci. 351 (3), 244-252. doi:10.1016/ j.amjms.2015.12.011

Chen, Y., Yang, D., Yang, C., Zheng, L., Huang, K., Yang, C., et al. (2020a). Response to Comment on Chen et al. Clinical Characteristics and Outcomes of Patients With Diabetes and COVID-19 in Association With Glucose-Lowering Medication. Diabetes Care 2020;43:1399-1407. Diabetes Care 43 (7), e165-1407. doi:10.2337/dci20-0035

Chen, Z., Yu, J., Fu, M., Dong, R., Yang, Y., Luo, J., et al. (2020b). Dipeptidyl Peptidase-4 Inhibition Improves Endothelial Senescence by Activating AMPK/ SIRT1/Nrf2 Signaling Pathway. Biochem. Pharmacol. 177, 113951. doi:10.1016/ j.bcp.2020.113951

Colice, G., Price, D., Gerhardsson De Verdier, M., Rabon-Stith, K., Ambrose, C., Cappell, K., et al. (2017). The Effect of DPP-4 Inhibitors on Asthma Control: an Administrative Database Study to Evaluate a Potential Pathophysiological Relationship. Pragmat Obs Res. 8, 231-240. doi:10.2147/por.s144018 
Dimitrova, M., Ivanov, I., Todorova, R., Stefanova, N., Moskova-Doumanova, V., Topouzova-Hristova, T., et al. (2012). Comparison of the Activity Levels and Localization of Dipeptidyl Peptidase IV in normal and Tumor Human Lung Cells. Tissue Cell 44 (2), 74-79. doi:10.1016/j.tice.2011.11.003

Fadini, G. P., Morieri, M. L., Longato, E., Bonora, B. M., Pinelli, S., Selmin, E., et al. (2020). Exposure to Dipeptidyl-Peptidase-4 Inhibitors and COVID-19 Among People With Type 2 Diabetes: A Case-Control Study. Diabetes Obes Metab. 22 (10), 1946-1950. doi:10.1111/dom.14097

Fleischer, B. (1994). CD26: a Surface Protease Involved in T-Cell Activation. Immunol. Today 15 (4), 180-184. doi:10.1016/0167-5699(94)90316-6

Fontes Pirozzi, F., Lima Favaro, G., Lima Favaro, D. T., Rinaldo Favaro, C., Gouvea Faria, M. A., de Quadros, L. G., et al. (2017). Vildagliptin Promotes Improvement in Pulmonary Arterial Hypertension: Incretin-Based Therapy at a Follow-Up of 3 Years. Lung Breath J. 1 (1), 1-2. doi:10.15761/LBJ.1000105

Gangadharan Komala, M., Gross, S., Zaky, A., Pollock, C., and Panchapakesan, U. (2016). Saxagliptin Reduces Renal Tubulointerstitial Inflammation, Hypertrophy and Fibrosis in Diabetes. Nephrology (Carlton) 21 (5), 423-431. doi:10.1111/nep.12618

Gao, A. C., Lou, W., Dong, J. T., and Isaacs, J. T. (1997). CD44 Is a Metastasis Suppressor Gene for Prostatic Cancer Located on Human Chromosome 11p13. Cancer Res. 57 (5), 846-849.

Gonzalez-Gronow, M., Grenett, H. E., Weber, M. R., Gawdi, G., and Pizzo, S. V. (2001). Interaction of Plasminogen with Dipeptidyl Peptidase IV Initiates a Signal Transduction Mechanism Which Regulates Expression of Matrix Metalloproteinase- 9 by Prostate Cancer Cells. Biochem. J. 355 ( $\mathrm{Pt} \mathrm{2),}$ 397-407. doi:10.1042/0264-6021:3550397

Gorrell, M. D. (2005). Dipeptidyl Peptidase IV and Related Enzymes in Cell Biology and Liver Disorders. Clin. Sci. (Lond) 108 (4), 277-292. doi:10.1042/ cs20040302

Hariyanto, T. I., and Kurniawan, A. (2021). Dipeptidyl Peptidase 4 (DPP4) Inhibitor and Outcome from Coronavirus Disease 2019 (COVID-19) in Diabetic Patients: a Systematic Review, Meta-Analysis, and Meta-Regression. J. Diabetes Metab. Disord. 20, 1-8. doi:10.1007/s40200-021-00777-4

Hatano, R., Ohnuma, K., Yamamoto, J., Dang, N. H., and Morimoto, C. (2013). CD26-mediated Co-stimulation in Human CD8(+) T Cells Provokes Effector Function via Pro-inflammatory Cytokine Production. Immunology 138 (2), 165-172. doi:10.1111/imm.12028

Havre, P. A., Abe, M., Urasaki, Y., Ohnuma, K., Morimoto, C., and Dang, N. H. (2008). The Role of CD26/dipeptidyl Peptidase IV in Cancer. Front. Biosci. 13, 1634-1645. doi:10.2741/2787

Helal, M. G., Megahed, N. A., and Abd Elhameed, A. G. (2019). Saxagliptin Mitigates Airway Inflammation in a Mouse Model of Acute Asthma via Modulation of NF-kB and TLR4. Life Sci. 239, 117017. doi:10.1016/ j.lfs.2019.117017

Herrlich, P., Morrison, H., Sleeman, J., Orian-Rousseau, V., König, H., WegRemers, S., et al. (2000). CD44 Acts Both as a Growth- and InvasivenessPromoting Molecule and as a Tumor-Suppressing Cofactor. Ann. N. Y Acad. Sci. 910, 106-118. doi:10.1111/j.1749-6632.2000.tb06704.x

Hildebrandt, M., Rose, M., Rüter, J., Salama, A., Mönnikes, H., and Klapp, B. F. (2001). Dipeptidyl Peptidase IV (DP IV, CD26) in Patients with Inflammatory Bowel Disease. Scand. J. Gastroenterol. 36 (10), 1067-1072. doi:10.1080/ 003655201750422675

Hoeper, M. M., Humbert, M., Souza, R., Idrees, M., Kawut, S. M., Sliwa-Hahnle, K., et al. (2016). A Global View of Pulmonary Hypertension. Lancet Respir. Med. 4 (4), 306-322. doi:10.1016/s2213-2600(15)00543-3

Inn, K. S., Kim, Y., Aigerim, A., Park, U., Hwang, E. S., Choi, M. S., et al. (2018). Reduction of Soluble Dipeptidyl Peptidase 4 Levels in Plasma of Patients Infected with Middle East Respiratory Syndrome Coronavirus. Virology 518, 324-327. doi:10.1016/j.virol.2018.03.015

Israelsen, S. B., Pottegård, A., Sandholdt, H., Madsbad, S., Thomsen, R. W., and Benfield, T. (2021). Comparable COVID-19 Outcomes With Current Use of GLP-1 Receptor Agonists, DPP-4 Inhibitors or SGLT-2 Inhibitors Among Patients With Diabetes Who Tested Positive for SARS-CoV-2. Diabetes Obes Metab. 23 (6), 1397-1401. doi:10.1111/dom.14329

Jang, J.-H., Janker, F., Arni, S., Yamada, Y., Weder, W., and Jungraithmayr, W. (2017). MA04.10 Lung Cancer Growth Is Suppressed by CD26/DPP4Inhibition via Enhanced NK Cell and Macrophage Recruitment. J. Thorac. Oncol. 12 (1), S362-S363. doi:10.1016/j.jtho.2016.11.404
Jang, J. H., Baerts, L., Waumans, Y., De Meester, I., Yamada, Y., Limani, P., et al. (2015). Suppression of Lung Metastases by the CD26/DPP4 Inhibitor Vildagliptin in Mice. Clin. Exp. Metastasis 32 (7), 677-687. doi:10.1007/ s10585-015-9736-z

Jang, J. H., Janker, F., De Meester, I., Arni, S., Borgeaud, N., Yamada, Y., et al. (2019). The CD26/DPP4-Inhibitor Vildagliptin Suppresses Lung Cancer Growth via Macrophage-Mediated NK Cell Activity. Carcinogenesis 40 (2), 324-334. doi:10.1093/carcin/bgz009

Kajiyama, H., Kikkawa, F., Suzuki, T., Shibata, K., Ino, K., and Mizutani, S. (2002). Prolonged Survival and Decreased Invasive Activity Attributable to Dipeptidyl Peptidase IV Overexpression in Ovarian Carcinoma. Cancer Res. 62 (10), 2753-2757. doi:10.1002/cncr.10625

Kawasaki, T., Chen, W., Htwe, Y. M., Tatsumi, K., and Dudek, S. M. (2018). DPP4 Inhibition by Sitagliptin Attenuates LPS-Induced Lung Injury in Mice. Am. J. Physiol. Lung Cell Mol Physiol 315 (5), L834-1845. doi:10.1152/ ajplung.00031.2018

Kim, K. M., Noh, J. H., Bodogai, M., Martindale, J. L., Yang, X., Indig, F. E., et al. (2017). Identification of Senescent Cell Surface Targetable Protein DPP4. Genes Dev. 31 (15), 1529-1534. doi:10.1101/gad.302570.117

Klemann, C., Wagner, L., Stephan, M., and von Hörsten, S. (2016). Cut to the chase: a Review of CD26/dipeptidyl Peptidase-4's (DPP4) Entanglement in the Immune System. Clin. Exp. Immunol. 185 (1), 1-21. doi:10.1111/cei.12781

Kruschinski, C., Skripuletz, T., Bedoui, S., Tschernig, T., Pabst, R., Nassenstein, C., et al. (2005). CD26 (Dipeptidyl-peptidase IV)-dependent Recruitment of $\mathrm{T}$ Cells in a Rat Asthma Model. Clin. Exp. Immunol. 139 (1), 17-24. doi:10.1111/j.1365-2249.2005.02666.x

Lay, A. J., Zhang, H. E., Mccaughan, G. W., and Gorrell, M. D. (2019). Fibroblast Activation Protein in Liver Fibrosis. Front. Biosci. (Landmark Ed. 24, 1-17. doi: $10.2741 / 4706$

Lee, D. S., Lee, E. S., Alam, M. M., Jang, J. H., Lee, H. S., Oh, H., et al. (2016). Soluble DPP-4 Up-Regulates Toll-like Receptors and Augments Inflammatory Reactions, Which Are Ameliorated by Vildagliptin or Mannose-6Phosphate. Metabolism 65 (2), 89-101. doi:10.1016/j.metabol.2015.10.002

Lee, S. Y., Wu, S. T., Liang, Y. J., Su, M. J., Huang, C. W., Jao, Y. H., et al. (2020). Soluble Dipeptidyl Peptidase-4 Induces Fibroblast Activation through Proteinase-Activated Receptor-2. Front. Pharmacol. 11, 552818. doi:10.3389/ fphar.2020.552818

Li, Y., Yang, L., Dong, L., Yang, Z. W., Zhang, J., Zhang, S. L., et al. (2019). Crosstalk between the Akt/mTORC1 and NF-Kb Signaling Pathways Promotes Hypoxia-Induced Pulmonary Hypertension by Increasing DPP4 Expression in PASMCs. Acta Pharmacol. Sin 40 (10), 1322-1333. doi:10.1038/s41401-019-0272-2

Liu, Y., and Qi, Y. (2020). Vildagliptin, a CD26/DPP4 Inhibitor, Ameliorates Bleomycin-Induced Pulmonary Fibrosis via Regulating the Extracellular Matrix. Int. Immunopharmacol 87, 106774. doi:10.1016/j.intimp.2020.106774

Matteucci, E., and Giampietro, O. (2009). Dipeptidyl Peptidase-4 (CD26): Knowing the Function before Inhibiting the Enzyme. Curr. Med. Chem. 16 (23), 2943-2951. doi:10.2174/092986709788803114

Meyerholz, D. K., Lambertz, A. M., and Mccray, P. B., Jr. (2016). Dipeptidyl Peptidase 4 Distribution in the Human Respiratory Tract: Implications for the Middle East Respiratory Syndrome. Am. J. Pathol. 186 (1), 78-86. doi:10.1016/ j.ajpath.2015.09.014

Mirani, M., Favacchio, G., Carrone, F., Betella, N., Biamonte, E., Morenghi, E., et al. (2020). Impact of Comorbidities and Glycemia at Admission and Dipeptidyl Peptidase 4 Inhibitors in Patients with Type 2 Diabetes with COVID-19: A Case Series from an Academic Hospital in Lombardy, Italy. Diabetes Care 43 (12), 3042-3049. doi:10.2337/dc20-1340

Mitchell, J., Dimov, V., and Townley, R. G. (2010). IL-13 and the IL-13 Receptor as Therapeutic Targets for Asthma and Allergic Disease. Curr. Opin. Investig. Drugs 11 (5), 527-534. doi:10.1016/j.cct.2010.03.006

Nader, M. A. (2015). Inhibition of Airway Inflammation and Remodeling by Sitagliptin in Murine Chronic Asthma. Int. Immunopharmacol 29 (2), 761-769. doi:10.1016/j.intimp.2015.08.043

Nieto-Fontarigo, J. J., González-Barcala, F. J., San José, E., Arias, P., Nogueira, M., and Salgado, F. J. (2019). CD26 and Asthma: a Comprehensive Review. Clin. Rev. Allergy Immunol. 56 (2), 139-160. doi:10.1007/s12016-016-8578-z

Noh, Y., Oh, I. S., Jeong, H. E., Filion, K. B., Yu, O. H. Y., and Shin, J. Y. (2021). Association Between DPP-4 Inhibitors and COVID-19-Related Outcomes 
Among Patients With Type 2 Diabetes. Diabetes Care. 44 (4), e64-e66. doi:10.2337/dc20-1824

Ohnuma, K., Haagmans, B. L., Hatano, R., Raj, V. S., Mou, H., Iwata, S., et al. (2013). Inhibition of Middle East Respiratory Syndrome Coronavirus Infection by Anti-CD26 Monoclonal Antibody. J. Virol. 87 (24), 13892-13899. doi:10.1128/jvi.02448-13

Ohnuma, K., Hosono, O., Dang, N. H., and Morimoto, C. (2011). Dipeptidyl Peptidase in Autoimmune Pathophysiology. Adv. Clin. Chem. 53, 51-84. doi:10.1016/b978-0-12-385855-9.00003-5

Okamoto, T., Iwata, S., Yamazaki, H., Hatano, R., Komiya, E., Dang, N. H., et al. (2014). CD9 Negatively Regulates CD26 Expression and Inhibits CD26Mediated Enhancement of Invasive Potential of Malignant Mesothelioma Cells. PLoS One 9 (1), e86671. doi:10.1371/journal.pone.0086671

Pal, R., Banerjee, M., Mukherjee, S., Bhogal, R. S., Kaur, A., and Bhadada, S. K. (2021). Dipeptidyl Peptidase-4 Inhibitor Use and Mortality in COVID-19 Patients with Diabetes Mellitus: an Updated Systematic Review and MetaAnalysis. Ther. Adv. Endocrinol. Metab. 12, 2042018821996482. doi:10.1177/ 2042018821996482

Pan, K., Ohnuma, K., Morimoto, C., and Dang, N. H. (2021). CD26/Dipeptidyl Peptidase IV and its Multiple Biological Functions. Cureus 13 (2), e13495. doi:10.7759/cureus.13495

Pang, R., Law, W. L., Chu, A. C., Poon, J. T., Lam, C. S., Chow, A. K., et al. (2010). A Subpopulation of CD26+ Cancer Stem Cells with Metastatic Capacity in Human Colorectal Cancer. Cell Stem Cell 6 (6), 603-615. doi:10.1016/ j.stem.2010.04.001

Pérez-Belmonte, L. M., Torres-Peña, J. D., López-Carmona, M. D., AyalaGutiérrez, M. M., Fuentes-Jiménez, F., Huerta, L. J., et al. (2020). Mortality and Other Adverse Outcomes in Patients With Type 2 Diabetes Mellitus Admitted for COVID-19 in Association With Glucose-Lowering Drugs: A Nationwide Cohort Study. BMC Med. 18 (1), 359. doi:10.1186/s12916-020$01832-2$

Poole, A., Urbanek, C., Eng, C., Schageman, J., Jacobson, S., O'connor, B. P., et al. (2014). Dissecting Childhood Asthma with Nasal Transcriptomics Distinguishes Subphenotypes of Disease. J. Allergy Clin. Immunol. 133 (3), 670-678. doi:10.1016/j.jaci.2013.11.025

Pro, B., and Dang, N. H. (2004). CD26/dipeptidyl Peptidase IV and its Role in Cancer. Histol. Histopathol 19 (4), 1345-1351. doi:10.14670/hh-19.1345

Radzikowska, U., Ding, M., Tan, G., Zhakparov, D., Peng, Y., Wawrzyniak, P., et al. (2020). Distribution of ACE2, CD147, CD26, and Other SARS-CoV-2 Associated Molecules in Tissues and Immune Cells in Health and in Asthma, COPD, Obesity, Hypertension, and COVID-19 Risk Factors. Allergy 75 (11), 2829-2845. doi:10.1111/all.14429

Raj, V. S., Mou, H., Smits, S. L., Dekkers, D. H., Müller, M. A., Dijkman, R., et al. (2013). Dipeptidyl Peptidase 4 Is a Functional Receptor for the Emerging Human Coronavirus-EMC. Nature 495 (7440), 251-254. doi:10.1038/ nature12005

Raj, V. S., Smits, S. L., Provacia, L. B., Van Den Brand, J. M., Wiersma, L., Ouwendijk, W. J., et al. (2014). Adenosine Deaminase Acts as a Natural Antagonist for Dipeptidyl Peptidase 4-mediated Entry of the Middle East Respiratory Syndrome Coronavirus. J. Virol. 88 (3), 1834-1838. doi:10.1128/ jvi.02935-13

Rakhmat, I. I., Kusmala, Y. Y., Handayani, D. R., Juliastuti, H., Nawangsih, E. N., Wibowo, A., et al. (2021). Dipeptidyl Peptidase-4 (DPP-4) Inhibitor and Mortality in Coronavirus Disease 2019 (COVID-19) - A Systematic Review, Meta-Analysis, and Meta-Regression. Diabetes Metab. Syndr. 15 (3), 777-782. doi:10.1016/j.dsx.2021.03.027

Ranade, K., Pham, T. H., Damera, G., Brohawn, P. Z., Pilataxi, F., Kuziora, M., et al. (2016). Dipeptidyl Peptidase-4 (DPP-4) Is a Novel Predictive Biomarker for the Investigational Anti-IL-13 Targeted Therapy Tralokinumab. Am. J. Respir. Crit. Care Med. 193, A4332.

Rhee, S. Y., Lee, J., Nam, H., Kyoung, D. S., Shin, D. W., and Kim, D. J. (2021). Effects of a DPP-4 Inhibitor and RAS Blockade on Clinical Outcomes of Patients with Diabetes and COVID-19. Diabetes Metab. J. 45 (2), 251-259. doi:10.4093/dmj.2020.0206

Richeldi, L., Collard, H. R., and Jones, M. G. (2017). Idiopathic Pulmonary Fibrosis. Lancet 389 (10082), 1941-1952. doi:10.1016/s0140-6736(17)30866-8

Rohmann, N., Schlicht, K., Geisler, C., Hollstein, T., Knappe, C., Krause, L., et al. (2021). Circulating sDPP-4 Is Increased in Obesity and Insulin Resistance but Is
Not Related to Systemic Metabolic Inflammation. J. Clin. Endocrinol. Metab. 106 (2), e592-e601. doi:10.1210/clinem/dgaa758

Roussel, R., Darmon, P., Pichelin, M., Goronflot, T., Abouleka, Y., Ait Bachir, L., et al. (2021). Use of Dipeptidyl Peptidase-4 Inhibitors and Prognosis of COVID-19 in Hospitalized Patients with Type 2 Diabetes: A Propensity Score Analysis from the CORONADO Study. Diabetes Obes. Metab. 23 (5), 1162-1172. doi:10.1111/dom.14324

Sato, T., Yamochi, T., Yamochi, T., Aytac, U., Ohnuma, K., Mckee, K. S., et al. (2005). CD26 Regulates P38 Mitogen-Activated Protein Kinasedependent Phosphorylation of Integrin Beta1, Adhesion to Extracellular Matrix, and Tumorigenicity of T-Anaplastic Large Cell Lymphoma Karpas 299. Cancer Res. 65 (15), 6950-6956. doi:10.1158/ 0008-5472.can-05-0647

Schafer, M. J., White, T. A., Iijima, K., Haak, A. J., Ligresti, G., Atkinson, E. J., et al. (2017). Cellular Senescence Mediates Fibrotic Pulmonary Disease. Nat. Commun. 8, 14532. doi:10.1038/ncomms 14532

Schuetz, C. A., Ong, S. H., and Blüher, M. (2015). Clinical Trial Simulation Methods for Estimating the Impact of DPP-4 Inhibitors on Cardiovascular Disease. Clinicoecon Outcomes Res. 7, 313-323. doi:10.2147/ceor.s75935

Sedo, A., Krepela, E., Kasafírek, E., Kraml, J., and Kadlecová, L. (1991). Dipeptidyl Peptidase IV in the Human Lung and Spinocellular Lung Cancer. Physiol. Res. 40 (3), 359-362.

Seys, L. J. M., Widagdo, W., Verhamme, F. M., Kleinjan, A., Janssens, W., Joos, G. F., et al. (2018). DPP4, the Middle East Respiratory Syndrome Coronavirus Receptor, Is Upregulated in Lungs of Smokers and Chronic Obstructive Pulmonary Disease Patients. Clin. Infect. Dis. 66 (1), 45-53. doi:10.1093/cid/ cix741

Shao, S., Xu, Q., Yu, X., Pan, R., and Chen, Y. (2020). Dipeptidyl Peptidase 4 Inhibitors and Their Potential Immune Modulatory Functions. Pharmacol. Ther. 209, 107503. doi:10.1016/j.pharmthera.2020.107503

Shingu, K., Helfritz, A., Zielinska-Skowronek, M., Meyer-Olson, D., Jacobs, R., Schmidt, R. E., et al. (2003). CD26 Expression Determines Lung Metastasis in Mutant F344 Rats: Involvement of NK Cell Function and Soluble CD26. Cancer Immunol. Immunother. 52 (9), 546-554. doi:10.1007/s00262-003-0392-9

Shiobara, T., Chibana, K., Watanabe, T., Arai, R., Horigane, Y., Nakamura, Y., et al. (2016). Dipeptidyl Peptidase-4 Is Highly Expressed in Bronchial Epithelial Cells of Untreated Asthma and it Increases Cell Proliferation along with Fibronectin Production in Airway Constitutive Cells. Respir. Res. 17, 28. doi:10.1186/ s12931-016-0342-7

Silverii, G. A., Monami, M., Cernigliaro, A., Vigneri, E., Guarnotta, V., Scondotto, S., et al. (2021). Are Diabetes and its Medications Risk Factors for the Development of COVID-19? Data From a Population-Based Study in Sicily. Nutr Metab Cardiovasc Dis. 31 (2), 396-398. doi:10.1016/ j.numecd.2020.09.028

Soare, A., Györfi, H. A., Matei, A. E., Dees, C., Rauber, S., Wohlfahrt, T., et al. (2020). Dipeptidylpeptidase 4 as a Marker of Activated Fibroblasts and a Potential Target for the Treatment of Fibrosis in Systemic Sclerosis. Arthritis Rheumatol. 72 (1), 137-149. doi:10.1002/art.41058

Solerte, S. B., D'addio, F., Trevisan, R., Lovati, E., Rossi, A., Pastore, I., et al. (2020a). Sitagliptin Treatment at the Time of Hospitalization Was Associated with Reduced Mortality in Patients with Type 2 Diabetes and COVID-19: A Multicenter, Case-Control, Retrospective, Observational Study. Diabetes Care 43 (12), 2999-3006. doi:10.2337/dc20-1521

Solerte, S. B., Di Sabatino, A., Galli, M., and Fiorina, P. (2020b). Dipeptidyl Peptidase-4 (DPP4) Inhibition in COVID-19. Acta Diabetol. 57 (7), 779-783. doi:10.1007/s00592-020-01539-z

Somborac-Bačura, A., Buljević, S., Rumora, L., Čulić, O., Detel, D., Pancirov, D., et al. (2012). Decreased Soluble Dipeptidyl Peptidase IV Activity as a Potential Serum Biomarker for COPD. Clin. Biochem. 45 (15), 1245-1250. doi:10.1016 j.clinbiochem.2012.04.023

Strollo, R., Maddaloni, E., Dauriz, M., Pedone, C., Buzzetti, R., and Pozzilli, P. (2021). Use of DPP4 Inhibitors in Italy Does Not Correlate with Diabetes Prevalence Among COVID-19 Deaths. Diabetes Res. Clin. Pract. 171, 108444. doi:10.1016/j.diabres.2020.108444

Suzuki, T., Tada, Y., Gladson, S., Nishimura, R., Shimomura, I., Karasawa, S., et al. (2017). Vildagliptin Ameliorates Pulmonary Fibrosis in LipopolysaccharideInduced Lung Injury by Inhibiting Endothelial-To-Mesenchymal Transition. Respir. Res. 18 (1), 177. doi:10.1186/s12931-017-0660-4 
Tai, W., He, L., Zhang, X., Pu, J., Voronin, D., Jiang, S., et al. (2020). Characterization of the Receptor-Binding Domain (RBD) of 2019 Novel Coronavirus: Implication for Development of RBD Protein as a Viral Attachment Inhibitor and Vaccine. Cell Mol Immunol 17 (6), 613-620. doi:10.1038/s41423-020-0400-4

Tremblay, A. J., Lamarche, B., Deacon, C. F., Weisnagel, S. J., and Couture, P. (2011). Effect of Sitagliptin Therapy on Postprandial Lipoprotein Levels in Patients with Type 2 Diabetes. Diabetes Obes. Metab. 13 (4), 366-373. doi:10.1111/j.1463-1326.2011.01362.x

Van Der Velden, V. H., and Hulsmann, A. R. (1999). Peptidases: Structure, Function and Modulation of Peptide-Mediated Effects in the Human Lung. Clin. Exp. Allergy 29 (4), 445-456. doi:10.1046/j.1365-2222.1999.00462.x

Vankadari, N., and Wilce, J. A. (2020). Emerging WuHan (COVID-19) Coronavirus: Glycan Shield and Structure Prediction of Spike Glycoprotein and its Interaction with Human CD26. Emerg. Microbes Infect. 9 (1), 601-604. doi:10.1080/22221751.2020.1739565

Viby, N. E., Isidor, M. S., Buggeskov, K. B., Poulsen, S. S., Hansen, J. B., and Kissow, H. (2013). Glucagon-like Peptide-1 (GLP-1) Reduces Mortality and Improves Lung Function in a Model of Experimental Obstructive Lung Disease in Female Mice. Endocrinology 154 (12), 4503-4511. doi:10.1210/en.2013-1666

Wang, J., Yu, M., Xu, J., Cheng, Y., Li, X., Wei, G., et al. (2019). Glucagon-like Peptide-1 (GLP-1) Mediates the Protective Effects of Dipeptidyl Peptidase IV Inhibition on Pulmonary Hypertension. J. Biomed. Sci. 26 (1), 6. doi:10.1186/ s12929-019-0496-y

Wang, N., Shi, X., Jiang, L., Zhang, S., Wang, D., Tong, P., et al. (2013). Structure of MERS-CoV Spike Receptor-Binding Domain Complexed with Human Receptor DPP4. Cell Res 23 (8), 986-993. doi:10.1038/cr.2013.92

Wargny, M., Potier, L., Gourdy, P., Pichelin, M., Amadou, C., Benhamou, P. Y., et al. (2021). Predictors of Hospital Discharge and Mortality in Patients with Diabetes and COVID-19: Updated Results from the Nationwide CORONADO Study. Diabetologia 64 (4), 778-794. doi:10.1007/s00125-020-05351-w

Wesley, U. V., Albino, A. P., Tiwari, S., and Houghton, A. N. (1999). A Role for Dipeptidyl Peptidase IV in Suppressing the Malignant Phenotype of Melanocytic Cells. J. Exp. Med. 190 (3), 311-322. doi:10.1084/ jem.190.3.311

Wesley, U. V., Tiwari, S., and Houghton, A. N. (2004). Role for Dipeptidyl Peptidase IV in Tumor Suppression of Human Non Small Cell Lung Carcinoma Cells. Int. J. Cancer 109 (6), 855-866. doi:10.1002/ijc.20091

Willheim, M., Ebner, C., Baier, K., Kern, W., Schrattbauer, K., Thien, R., et al. (1997). Cell Surface Characterization of T Lymphocytes and Allergen-specific T Cell Clones: Correlation of CD26 Expression with T(H1) Subsets. J. Allergy Clin. Immunol. 100 (3), 348-355. doi:10.1016/s0091-6749(97)70248-3

Wronkowitz, N., Görgens, S. W., Romacho, T., Villalobos, L. A., Sánchez-Ferrer, C. F., Peiró, C., et al. (2014). Soluble DPP4 Induces Inflammation and Proliferation of Human Smooth Muscle Cells via Protease-Activated Receptor 2. Biochim. Biophys. Acta 1842 (9), 1613-1621. doi:10.1016/j.bbadis.2014.06.004

Xu, J., Wang, J., He, M., Han, H., Xie, W., Wang, H., et al. (2018). Dipeptidyl Peptidase IV (DPP-4) Inhibition Alleviates Pulmonary Arterial Remodeling in
Experimental Pulmonary Hypertension. Lab. Invest. 98 (10), 1333-1346. doi:10.1038/s41374-018-0080-1

Yamabe, T., Takakura, K., Sugie, K., Kitaoka, Y., Takeda, S., Okubo, Y., et al. (1997). Induction of the 2B9 Antigen/dipeptidyl Peptidase IV/CD26 on Human Natural Killer Cells by IL-2, IL-12 or IL-15. Immunology 91 (1), 151-158. doi:10.1046/j.1365-2567.1997.00230.x

Yan, S., Marguet, D., Dobers, J., Reutter, W., and Fan, H. (2003). Deficiency of CD26 Results in a Change of Cytokine and Immunoglobulin Secretion after Stimulation by Pokeweed Mitogen. Eur. J. Immunol. 33 (6), 1519-1527. doi:10.1002/eji.200323469

Yao, C., Guan, X., Carraro, G., Parimon, T., Liu, X., Huang, G., et al. (2021). Senescence of Alveolar Type 2 Cells Drives Progressive Pulmonary Fibrosis. Am. J. Respir. Crit. Care Med. 203 (6), 707-717. doi:10.1164/rccm.202004$1274 \mathrm{OC}$

Zaki, A. M., van Boheemen, S., Bestebroer, T. M., Osterhaus, A. D., and Fouchier, R. A. (2012). Isolation of a Novel Coronavirus from a Man with Pneumonia in Saudi Arabia. N. Engl. J. Med. 367 (19), 1814-1820. doi:10.1056/ NEJMoa1211721

Zhou, F., Yu, T., Du, R., Fan, G., Liu, Y., Liu, Z., et al. (2020a). Clinical Course and Risk Factors for Mortality of Adult Inpatients with COVID-19 in Wuhan, China: a Retrospective Cohort Study. Lancet 395 (10229), 1054-1062. doi:10.1016/s0140-6736(20)30566-3

Zhou, J. H., Wu, B., Wang, W. X., Lei, F., Cheng, X., Qin, J. J., et al. (2020b). No Significant Association between Dipeptidyl Peptidase-4 Inhibitors and Adverse Outcomes of COVID-19. World J. Clin. Cases 8 (22), 5576-5588. doi:10.12998/ wjcc.v8.i22.5576

Zhuge, F., Ni, Y., Nagashimada, M., Nagata, N., Xu, L., Mukaida, N., et al. (2016). DPP-4 Inhibition by Linagliptin Attenuates Obesity-Related Inflammation and Insulin Resistance by Regulating M1/M2 Macrophage Polarization. Diabetes 65 (10), 2966-2979. doi:10.2337/db16-0317

Conflict of Interest: The authors declare that the research was conducted in the absence of any commercial or financial relationships that could be construed as a potential conflict of interest.

Publisher's Note: All claims expressed in this article are solely those of the authors and do not necessarily represent those of their affiliated organizations, or those of the publisher, the editors and the reviewers. Any product that may be evaluated in this article, or claim that may be made by its manufacturer, is not guaranteed or endorsed by the publisher.

Copyright (c) 2021 Zhang, Tong, Zhang, Wang, Wang, Wang and Fan. This is an open-access article distributed under the terms of the Creative Commons Attribution License (CC BY). The use, distribution or reproduction in other forums is permitted, provided the original author(s) and the copyright owner(s) are credited and that the original publication in this journal is cited, in accordance with accepted academic practice. No use, distribution or reproduction is permitted which does not comply with these terms. 